\title{
Effects of Stem Moisture Content, Length of Lever Arm, Region of Cut and Cutting Attempts on the Cutting Efficiency of a Push-Type Cassava Stem Cutter and Harvester
}

\author{
A. Gbabo A ${ }^{1}$, I. S. Egbe-Okpenge ${ }^{2}$ and I. M. Gana ${ }^{3 *}$ \\ ${ }^{1}$ Department of Agricultural \&Bioresources Engineering, Federal University of Technology Minna, \\ Niger State, Nigeria \\ Email: agidides [AT] yahoo.com \\ ${ }^{2}$ Department of Agricultural \&Bioresources Engineering, Federal University of Technology Minna, \\ Niger State, Nigeria \\ ${ }^{3} \mathrm{~T}$ Department of Agricultural \& Bio-environmental Engineering, Federal Polytechnic Bida, \\ Niger State, Nigeria \\ ${ }^{*}$ Corresponding author's email: Ganaibro74 [AT] yahoo.com
}

\begin{abstract}
I Cassava harvesting is viewed as the most arduous operation in its production chain, involving three main sequential operations from stem cutting, soil loosening and then uprooting of the tubers. A semi-mechanised cassava stem cutter and harvester was developed to aid mitigate the drudgery involved in cassava harvesting. The machine was designed to carry out three main operations which include stem cutting, soil loosening and tuber harvesting. A precise knowledge of agronomic, physical and mechanical properties of the stem and factors affecting cassava harvesting most especially stem cutting plays a vital role in an attempt to overcome the existing challenges associated with the harvesting. The effects of stem girth, region of cut, cutting attempts and stem moisture content on cutting efficiency was investigated. The result of the experiment revealed that the cutting efficiency ranged from 3 to 99.5\%. The highest cutting efficiency of $99.5 \%$ was obtained from combination of stem moisture content of $85 \%$, length of lever arm from fulcrum of $65 \mathrm{~cm}$, region of cut above ground level of $30 \mathrm{~cm}$ and number of cutting attempts 3. The lowest cutting efficiency of $3 \%$ was obtained from combination of stem moisture content of $45 \%$, length of lever arm from fulcrum of $65 \mathrm{~cm}$, region of cut above ground level of $30 \mathrm{~cm}$ and number of cutting attempts 3 . The optimization process produced solutions whose desirability equals to 1 and the selected (most desirable) condition was found to be: stem moisture content (75\%), length of lever arm from fulcrum $(70 \mathrm{~cm})$, region of cut above ground level $(40 \mathrm{~cm})$ and cutting attempts (4), with cutting efficiency and desirability of $99.5 \%$ and 0.959 respectively. These findings are vital knowledge necessary in the development of cassava stem cutting and harvesting equipment.
\end{abstract}

Keywords - A Cassava harvester, cutter, efficiency, moisture, region of cut, stem

\section{INTRODUCTION}

Cassava (Manihot esculenta) is a herbaceous perennial woody shrub, consisting of $6 \%$ leaves, $44 \%$ stem and $50 \%$ roots, with moisture content ranges from 60 to 66. It is a tuberous starchy root with $32-35 \%$ carbohydrates content, a major source of calories that is processed into flour, starch and snacks [1]. Harvesting of cassava is one of the most important operations in cassava production line [2]. According to [3] for small scale farming it can be harvested without cutting the stems, but on industrial scale, the crop is harvested by first cutting the stems at a height of 20 to $40 \mathrm{~cm}$ above the ground after which an available or preferred method of uprooting the tubers off the ground is employed. [2] reported that cassava harvesting constitutes the highest production cost, involving a sequence of operations from stem cutting, soil loosening was necessary and then uprooting. The harvesting process could be carried out either by manual, semimechanised or by the use of mechanised equipment. The manual method is usually done by hand; cutting the lower part of stem and pulling the roots off the ground, then detaching them from the base of the plant after the upper parts of the stem are removed. Semi-mechanised harvesting involves improvised systems like the use of Levers and ropes to aid through the process of harvesting. [4] reported that harvesting with an improved manual harvesting tool saves about half 
the time required as compared to cutting and uprooting with bare hands. The mechanical harvesting of cassava involves the use of a harvesting implement hitched to a tractor to first cut and subsequently dig up the roots. This method is the most preferable but often unavailable or unaffordable to over 70 percent of farmers. [5] studied the mechanical properties of cassava stalks for the design of a cassava stalk cutting and recycling machine, the results of the study revealed that moisture content and region of cut were highly significant factors to be considered in stem cutting. According to [6] asserted that the average length, mass and diameter of cassava stalk decreases with decreasing moisture content and vice versa. Further analysis indicated that shear stress increased with decreasing moisture in the stem and increased with a change in the region of cut from upper section, having a smaller diameter, to a lower section, close to the root zone with a larger diameter. Thus, implying that, moisture content and region of cut had significant effects on the shear stress and cutting force required. Therefore, recommending that, cassava stalks be cut timely at relatively higher moisture contents to minimize cutting force requirement. This study attempts to explore and analyse the effects of cassava stem moisture and region of cut on the cutting efficiency of a developed push-type cassava stem cutter and harvester

\section{MATERIALS AND METHODS}

\subsection{Materials}

The following materials were used in the study in order to determine the effects of stem moisture, length of lever arm, region of cut and cutting attempt on the cutting efficiency of a push-type cassava stem cutter and harvester.

\subsubsection{Cassava Stem Samples}

A 15 months old cassava TME 419 variety stands cultivated on 50 by $50 \mathrm{~m}$ farm at Dabarako village, Bida Local Government Area, Niger state Nigeria was used for the study.

\subsubsection{Equipment}

A semi-mechanised cassava stem cutter and harvester developed in the Department of Agricultural and Bioresouses of Federal University of Technology, Minna, Niger State was used for the study [7]. As shown in Figure 1 the machine consists of three mechanisms for stem cutting, soil loosening and tuber harvesting, with special reference to the cutting mechanism. All three mechanisms where attached to the frame by means of temporal fasteners. The mechanism of a simple machine as the lever was employed in driving and powering all mechanisms of the machine. The first-class principle of levers, having the fulcrum in between the load and the effort was applied in the design and fabrication of the uprooting mechanism, the scraper and secateurs. While the second-class lever principle was adopted in the fabrication of the machine frame, with the load in between the effort and the fulcrum. The major components of the harvester are; the machine frame, the wheels, pruning shears (secateurs), lever controls, griping jaw, soil loosening component (scraper) and the harvester cab. The frame is a skeletal structure on which all other components are assembled. The machine was designed to run on two-wheels, situated at the front adopting a second-class lever principle, transmitting power obtained from the push force. The secateurs consist of two blades in parallel, pivotally linked at a point for cutting the stems $15 \mathrm{~cm}$ above the soil surface before harvesting. The griping jaw with a serrated groove/single jagged edge, wide enough to accommodate stem girts of between $20-70 \mathrm{~mm}$ was designed and fabricated to easily grip the stem at its base, close to ground surface, displacing the tubers from the soil at an increasing angle from $30 \mathrm{o}$ to the horizontal in order to uproot the tubers off the ground with the aid of the linked lever mechanism. The soil loosening component was built in form of a digger, with twin prongs used to loosen hard compact soils, at least $100 \mathrm{~mm}$ below the soil surface. While the harvester cabin was designed to provide shelter for the operator, from harsh weather conditions, like intense sunlight and rain. 


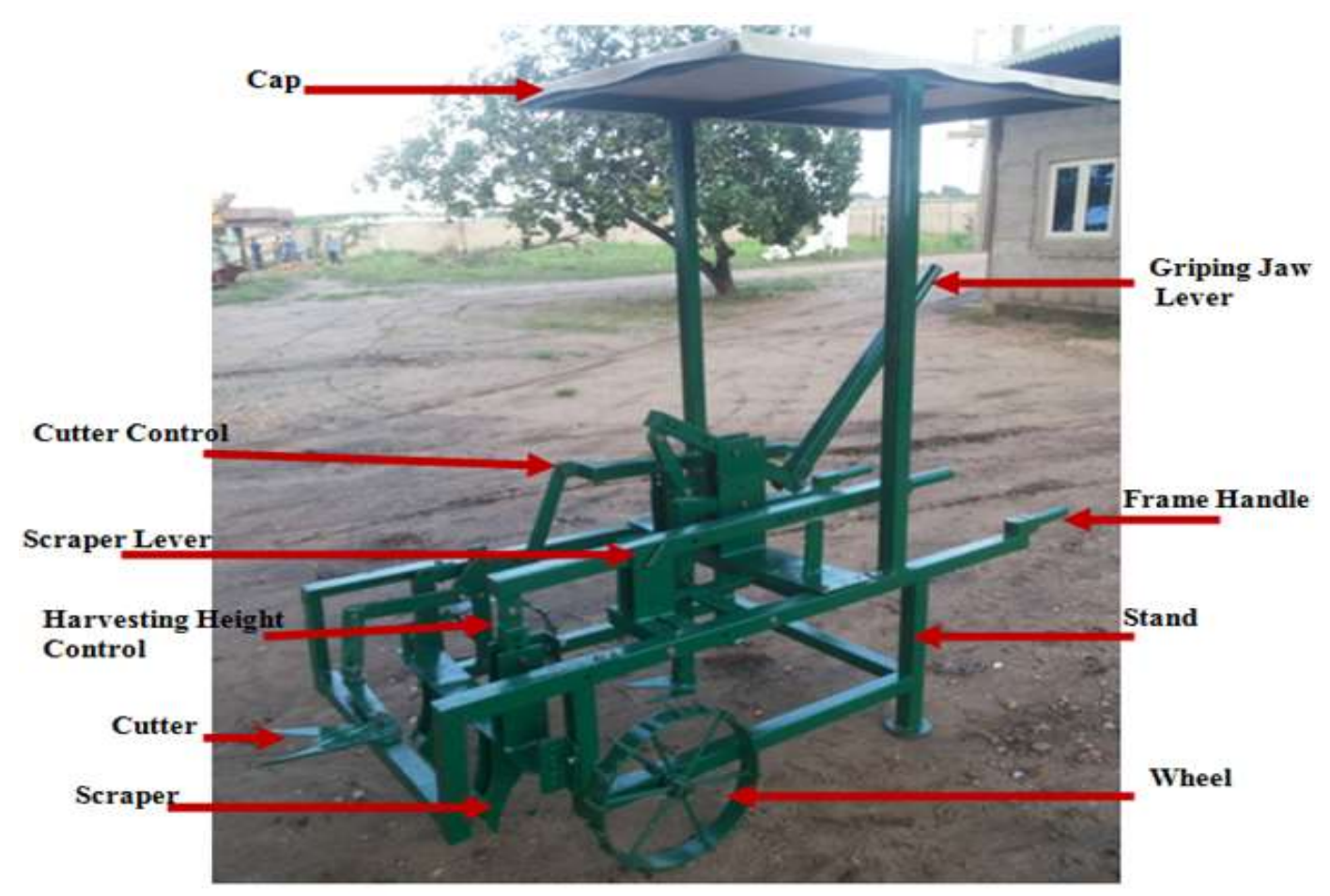

Figure 1: The Cassava Harvester and Stem Cutter

\subsection{Methods}

\subsubsection{Experimental Setup}

Fifty stem of the cassava TME 419 variety stands samples were randomly selected from the field. Their diameters were measured and recorded at a recommended coppicing height of $30-40 \mathrm{~cm}$ above ground level. The semimechanised cassava stem cutter and harvester was used to cut the cassava stem (Figure 1). An experiment was carried out to investigate the effects of stem moisture content (d.b), length of lever arm from fulcrum, region of cut above ground level and number of cutting attempts on cutting efficiency. The experiment was carried out at the farmers farm in Dabarako village, Bida Local Government Area, Niger state Nigeria.

\subsubsection{Moisture Content Determination}

The stem moisture content was determined to investigate the effects of varying moisture levels on cutting efficiency. This was done by randomly collecting stem samples of length $15 \mathrm{~cm}$ from fifty (50) different cassava stands. Each stalk sample was numbered and weighed on a digital lab scale before oven dried at a temperature of $150 \mathrm{o}$ for $18 \mathrm{hrs}$. Dry stalk samples were then carefully collected, re-weighed (using a weighing balance model JA303P, number 1505601) and recorded and the moisture determined. The method reported by [8] was used to determine the moisture content in the stem and is given in as follows;

$$
M C_{[d b]} \%=\frac{W_{w}-W_{d}}{W_{W}} \times 100
$$

Where, $\mathrm{MC}_{(\mathrm{d} . \mathrm{b})}$ is the percentage moisture content in dry basis $(\%), \mathrm{W}_{\mathrm{w}}$ is the weight of wet stalk $(\mathrm{g}), \mathrm{W}_{\mathrm{d}}$ is the weight of oven dried stalk $(\mathrm{g})$

\subsubsection{Diameter of the cassava stem}

Their diameters of the cassava stem samples were measured using a Vernier caliper (Gilson model) with calibration of $20 \mathrm{~cm}$ with error of 0.05 as reported by [9].

\subsection{Design of the Experiment}

In the testing the independent variables were varied at five levels; moisture content of $45,5565,75$ and $85 \%$ (db), length of Lever arm from fulcrum (cm) of 55, 60, 65, 70 and $75 \mathrm{~cm}$, region of cut above ground level of 10, 20, 30, 40 and $50 \mathrm{~cm}$, and number of cutting attempts of 1,2,3,4 and 5 to determine their effects on cutting efficiency of the equipment. The experimental design was designed as a function of independent variables of moisture content (A), length of Lever arm from fulcrum (B), region of cut above ground level (C) and number of cutting attempts (D) using central 
composite rotatable design (CCRD) of response surface methodology (rsm). In order to obtain the required data, the range of values of each of the three variables $(\mathrm{k})$ was determined as reported by [10] and [11] as presented in Table 3 . The objective function here was to minimise the effects of unexpected variability in the observed response. Stem cutting efficiency was considered as the response in this case.

\subsection{Statistical analysis}

Design expert software package (version7.0.0) was used for the regression and graphical analysis. A quadratic polynomial equation was developed to predict the response as a function of independent variables and their interaction. Analysis of variance (ANOVA) was carried out to estimate the effects of main variables and their potential interaction effects on the cutting efficiency [11].

\subsection{Performance Evaluation of the Machine}

The performance of the equipment was evaluated based on its cutting efficiency in order to recommend for its best performance using the following parameter:

\subsubsection{Cutting Efficiency}

The cutting blade was fixed on the frame at a recommended coppicing height of $30 \mathrm{~cm}$ above the ground surface. The Cutting efficiency was determined as reported by [12]

and is given as;

$$
P_{\varepsilon}=\frac{P_{F}}{P_{F}+U_{p r}} \times 100 \%
$$

Where, $P_{s}$ is the cutting efficiency $(\%), P_{r}$ is the number of stalks cut, $U_{p r}$ is the number of un-cut stalks,

\section{RESULTS AND DISCUSSION}

\subsection{Results}

The effects of stem moisture content (d.b), length of lever arm from fulcrum, region of cut above ground level and number of cutting attempts on cutting efficiency was investigated. The cutting efficiency ranged from 3 to $99.5 \%$. The highest cutting efficiency of $99.5 \%$ was obtained from combination of stem moisture content of $85 \%$, length of lever arm from fulcrum of $65 \mathrm{~cm}$, region of cut above ground level of $30 \mathrm{~cm}$ and number of cutting attempts 3 . The lowest cutting efficiency of $3 \%$ was obtained from combination of stem moisture content of $45 \%$, length of lever arm from fulcrum of $65 \mathrm{~cm}$, region of cut above ground level of $30 \mathrm{~cm}$ and number of cutting attempts 3 .

Table 1: Matrix transformation of five level- four factors central composite rotatable design of the experiment

\begin{tabular}{cccccccc}
\hline Std Run & $\begin{array}{c}\text { Stem moisture } \\
\text { content (\%) }\end{array}$ & $\begin{array}{c}\text { Length of lever } \\
\text { arm from } \\
\text { fulcrum }(\mathrm{cm})\end{array}$ & $\begin{array}{c}\text { Region of cut above } \\
\text { ground level }(\mathrm{cm})\end{array}$ & $\begin{array}{c}\text { Number of trial } \\
\text { (no) }\end{array}$ & $\begin{array}{c}\text { Cutting } \\
\text { efficiency }(\%)\end{array}$ & $\begin{array}{c}\text { Predicted } \\
\text { cutting } \\
\text { efficiency } \\
(\%)\end{array}$ \\
\hline 14 & 1 & 75 & 60 & 40 & 4 & 94.58 & 92.78 \\
15 & 2 & 55 & 70 & 40 & 4 & 50.32 & 50.61 \\
5 & 3 & 55 & 60 & 40 & 2 & 25.2 & 25.31 \\
9 & 4 & 55 & 60 & 20 & 4 & 45.3 & 45.94 \\
4 & 5 & 75 & 70 & 20 & 2 & 82.5 & 81.99 \\
30 & 6 & 65 & 65 & 30 & 3 & 66.45 & 62.97 \\
7 & 7 & 55 & 70 & 40 & 2 & 23.39 & 22.64 \\
8 & 8 & 75 & 70 & 40 & 2 & 82.35 & 81.13 \\
25 & 9 & 65 & 65 & 30 & 3 & 50.45 & 62.97 \\
20 & 10 & 65 & 75 & 30 & 3 & 67.19 & 68.52 \\
13 & 11 & 55 & 60 & 40 & 4 & 48.5 & 49.53 \\
22 & 12 & 65 & 65 & 50 & 3 & 68.5 & 68.82 \\
18 & 13 & 85 & 65 & 30 & 3 & 99.5 & 100 \\
17 & 14 & 45 & 65 & 30 & 3 & 3 & 1.99 \\
6 & 15 & 75 & 60 & 40 & 2 & 80.5 & 82.10 \\
29 & 16 & 65 & 65 & 30 & 3 & 65.5 & 62.97 \\
\hline
\end{tabular}




\begin{tabular}{cccccccc}
\hline 23 & 17 & 65 & 65 & 30 & 1 & 44.46 & 44.39 \\
2 & 18 & 75 & 60 & 20 & 2 & 80.5 & 79.63 \\
12 & 19 & 75 & 70 & 20 & 4 & 92.85 & 92.15 \\
1 & 20 & 55 & 60 & 20 & 2 & 25.5 & 26.00 \\
19 & 21 & 65 & 55 & 30 & 3 & 66.34 & 65.07 \\
24 & 22 & 65 & 65 & 30 & 5 & 78.63 & 78.77 \\
21 & 23 & 65 & 65 & 10 & 3 & 66.35 & 66.09 \\
11 & 24 & 55 & 70 & 20 & 4 & 51.45 & 50.36 \\
28 & 25 & 65 & 65 & 30 & 3 & 65.5 & 62.97 \\
10 & 26 & 75 & 60 & 20 & 4 & 84.77 & 86.03 \\
16 & 27 & 75 & 70 & 40 & 4 & 95.54 & 95.56 \\
26 & 28 & 65 & 65 & 30 & 3 & 65.45 & 62.97 \\
3 & 29 & 55 & 70 & 20 & 2 & 25.45 & 26.67 \\
27 & 30 & 65 & 65 & 30 & 3 & 64.45 & 92.78 \\
\hline
\end{tabular}

\subsection{Discussion}

Effects of the independent variables on cutting efficiency

The result of statistical analysis of variance (ANOVA) of the experimental was presented in Table 2. The effects, contribution, model coefficient, test for Lack-of-fit and the significance of the variables and their respective interaction on the stem cutting efficiency were determined as reported by [11]. A quadratic model was statistically significant for the responses. The significant model terms were identified at 95\% significance level. The Quadratic regression model equation developed to predict stem cutting efficiency with respect to independent variables were given as shown in Eq. (3) and Eq. (4).

Table 2: Regresional analysis of response of cutting efficiency

\begin{tabular}{|c|c|c|c|c|c|}
\hline Source & Coefficient & Standard & F-value & p-value & \\
\hline Model & 62.96667 & 1.531758 & 86.05447 & $1.01 \mathrm{E}-11$ & significant \\
\hline A-Stem Moisture Content & 24.645 & 0.765879 & 1035.469 & $2.95 \mathrm{E}-15$ & \\
\hline B-Length of Lever Arm from Fulcrum & 0.8625 & 0.765879 & 1.268229 & 0.277795 & \\
\hline C-Region of Cut above ground level & 0.681667 & 0.765879 & 0.79218 & 0.387494 & \\
\hline D-Number of Trial & 8.594167 & 0.765879 & 125.9178 & $1.08 \mathrm{E}-08$ & \\
\hline $\mathrm{AB}$ & 0.42375 & 0.938006 & 0.204083 & 0.657908 & \\
\hline $\mathrm{AC}$ & 0.79 & 0.938006 & 0.70932 & 0.412897 & \\
\hline $\mathrm{AD}$ & -3.38375 & 0.938006 & 13.01322 & 0.002586 & \\
\hline $\mathrm{BC}$ & -0.835 & 0.938006 & 0.792431 & 0.387421 & \\
\hline $\mathrm{BD}$ & 0.93875 & 0.938006 & 1.001586 & 0.332799 & \\
\hline $\mathrm{CD}$ & 1.0675 & 0.938006 & 1.295162 & 0.27295 & \\
\hline $\mathrm{AA}^{2}$ & -2.92125 & 0.716414 & 16.62681 & 0.00099 & \\
\hline $\mathrm{BA}^{2}$ & 0.9575 & 0.716414 & 1.786278 & 0.201301 & \\
\hline $\mathrm{CA}^{2}$ & 1.1225 & 0.716414 & 2.454959 & 0.138004 & \\
\hline $\mathrm{DA}^{2}$ & -0.3475 & 0.716414 & 0.235278 & 0.634645 & \\
\hline Lack of Fit & & & 0.055689 & 0.999896 & $\begin{array}{l}\text { not } \\
\text { significant }\end{array}$ \\
\hline R Squared & 0.9877 & & & & \\
\hline Adjusted R Squared & 0.9762 & & & & \\
\hline Predicted R Squared & 0.977 & & & & \\
\hline Adequate Precision & 37.1568 & & & & \\
\hline
\end{tabular}


The Model F-value of 86.05 implies the model is significant. There is only a $0.01 \%$ chance that an F-value this large could occur due to noise. The value of Probability > F less than 0.0500 indicate model terms are significant. In this case $\mathrm{A}, \mathrm{D}, \mathrm{AD}, \mathrm{A}^{2}$ are significant model terms. Values greater than 0.1000 indicate the model terms are not significant. It can be clearly observed that A had more significant effect on cutting efficiency with coefficient of estimate of 24.64 [13]. The Lack of Fit F-value of 0.06 implies the Lack of Fit is not significant relative to the pure error. There is a $99.99 \%$ chance that a Lack of Fit F-value this large could occur due to noise. In general, non-significant lack of fit was considered good indicative that the model equation can predict the response. The coefficient of determination $\mathrm{R}$ value of 0.9938 indicated that the model was able to predict $99.38 \%$ of the variance and only $0.62 \%$ of the total variance was not explained by the model. The Predicted $\mathrm{R}^{2}$ of 0.9770 is in reasonable agreement with the Adjusted $\mathrm{R}^{2}$ of 0.9762 ; i.e. the difference is less than 0.2 which indicated that the experimental data fitted better [14]. Adequate Precision value of 20.17 is above the desirable minimum value of 4 was reported by [11], this indicated that the model can be used to navigate the design space.

The regressed paste expelling efficiency model equation is given as

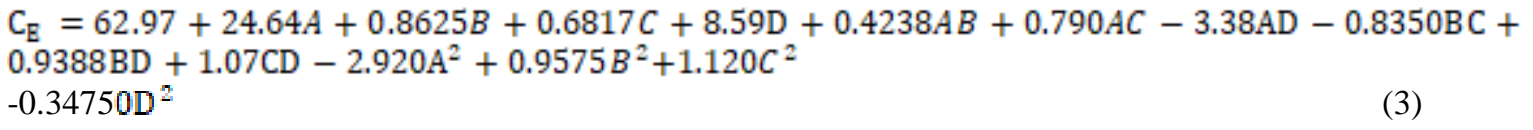

where, $\mathrm{C}_{\mathrm{E}}$ is the cutting efficiency $(\%)$, $\mathrm{A}$ is the stem moisture content $(\%), \mathrm{B}$ is the length of Lever arm from fulcrum $(\mathrm{cm}), \mathrm{C}$ is the region of cut above ground level $(\mathrm{cm}), \mathrm{D}$ is the number of cutting attempts (No)

The model equation was improved by removing insignificant model terms. Values greater than 0.1000 implies that the model terms are not (that is $\mathrm{B}, \mathrm{C}, \mathrm{AB}, \mathrm{AC}, \mathrm{BC}, \mathrm{BD}, \mathrm{CD}, \mathrm{B} 2, \mathrm{C} 2$, and $\mathrm{D} 2$ were not significant) and since these terms are insignificant the model was reduced to equation 2 from equation 1, in order to improve it [15].

The fitted paste expelling efficiency model equation is given as

$\mathrm{C}_{\mathrm{E}}=62.97+24.64 \mathrm{~A}+8.59 \mathrm{D}-3.38 \mathrm{AD}+0.9388 \mathrm{BD}-2.920 \mathrm{~A}^{2}$

It is important to add that the variables $\mathrm{A}$ and $\mathrm{D}$ in the model have positive co-efficient implying a direct proportionality. That is independent increase in A and D increased the cutting efficiency. The model equation obtained was simulated and the cutting efficiency was observed to be within the experimental range. From Table 1 the actual values of cutting efficiency were observed to be in close agreement with the predicted values. This is an indication to close agreement between the two values validating the need for the model equation to use to determine the optimum cutting efficiency at various operating condition.

Effects of stem moisture content and length of lever arm on cutting efficiency

The response surface and contour plot for cutting efficiency with respect to stem moisture content and length of lever arm are shown in Figures 2 and 3 respectively.

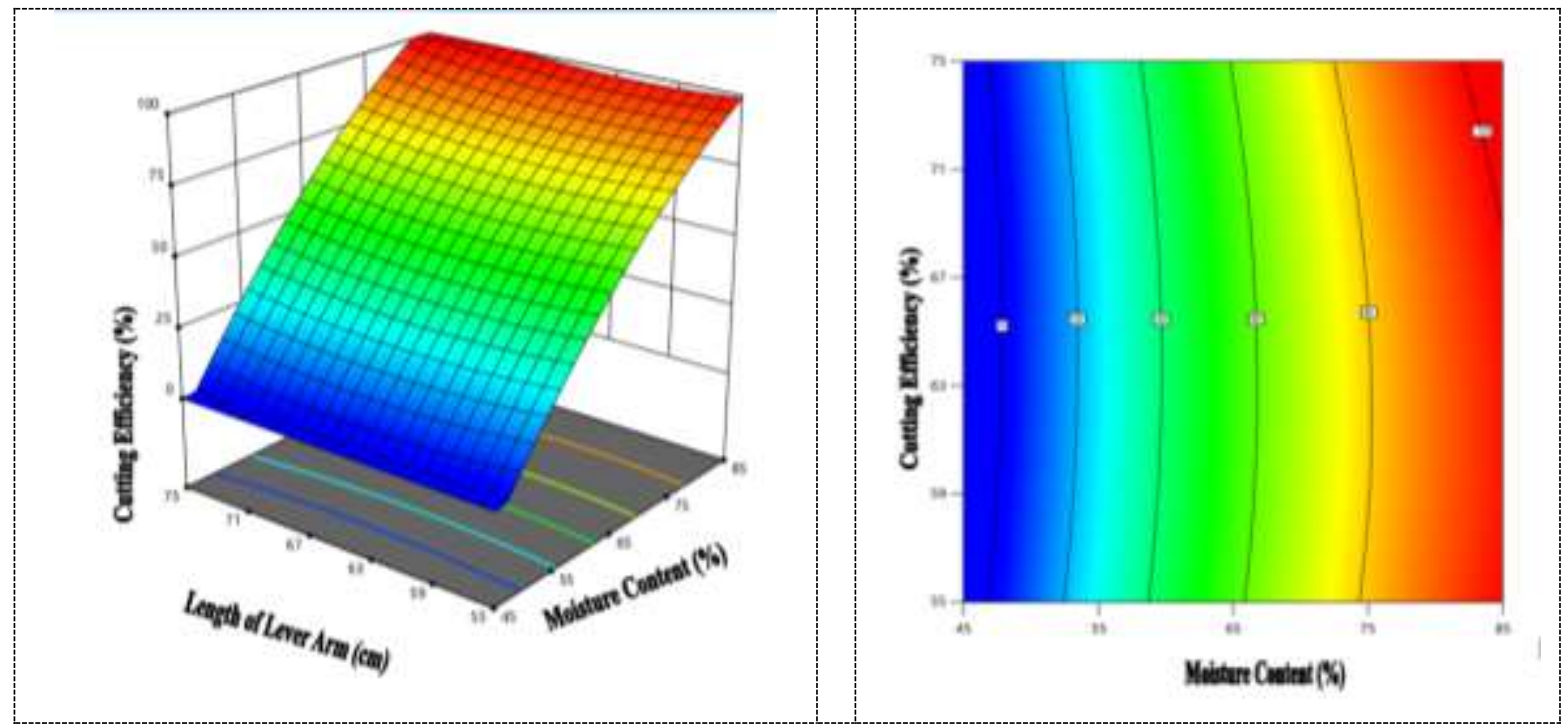




\section{Figure 2. Response surface of cutting efficiency with effects to length of lever arm and stem moisture content}

Figure 3. Contour plot of cutting efficiency with effects to length of lever arm and stem moisture content

The cutting efficiency increased from $0 \%$ to $99.9 \%$ with increased in stem moisture content from $45 \%$ to $85 \%$ M.C. This could be due to less shear stress required to cut the stem with high level of moisture. This in lined with an earlier finding reported by [5] and [6]. The stem moisture content had significant effects $(p \leq 0.05)$ with increase of $99.9 \%$ on the cutting efficiency. It can also be observed that the cutting efficiency remain constant with respect to length of lever arm from fulcrum. Therefore, length of lever arm had no any significant effects $(p \leq 0.05)$ on the cutting efficiency.

Effects of region of cut and number of trials on cutting efficiency

The response surface and contour plot for cutting efficiency with respect to region of cut and number of trial on cutting efficiency are shown in Figures 4 and 5 respectively. The cutting efficiency increased from $46 \%$ to $75 \%$ with increased in number of trials from 1 to 5 . This could be as result of reduction in the stem shear strength with increase in cutting attempt as asserted by [5]. The number of cutting trial had significant effects $(p \leq 0.05)$ with increase of $29 \%$ on the cutting efficiency. It can also be observed that the cutting efficiency remain constant with region of cut. Therefore, region of cut had no any significant effects $(p \leq 0.05)$ on the cutting efficiency.

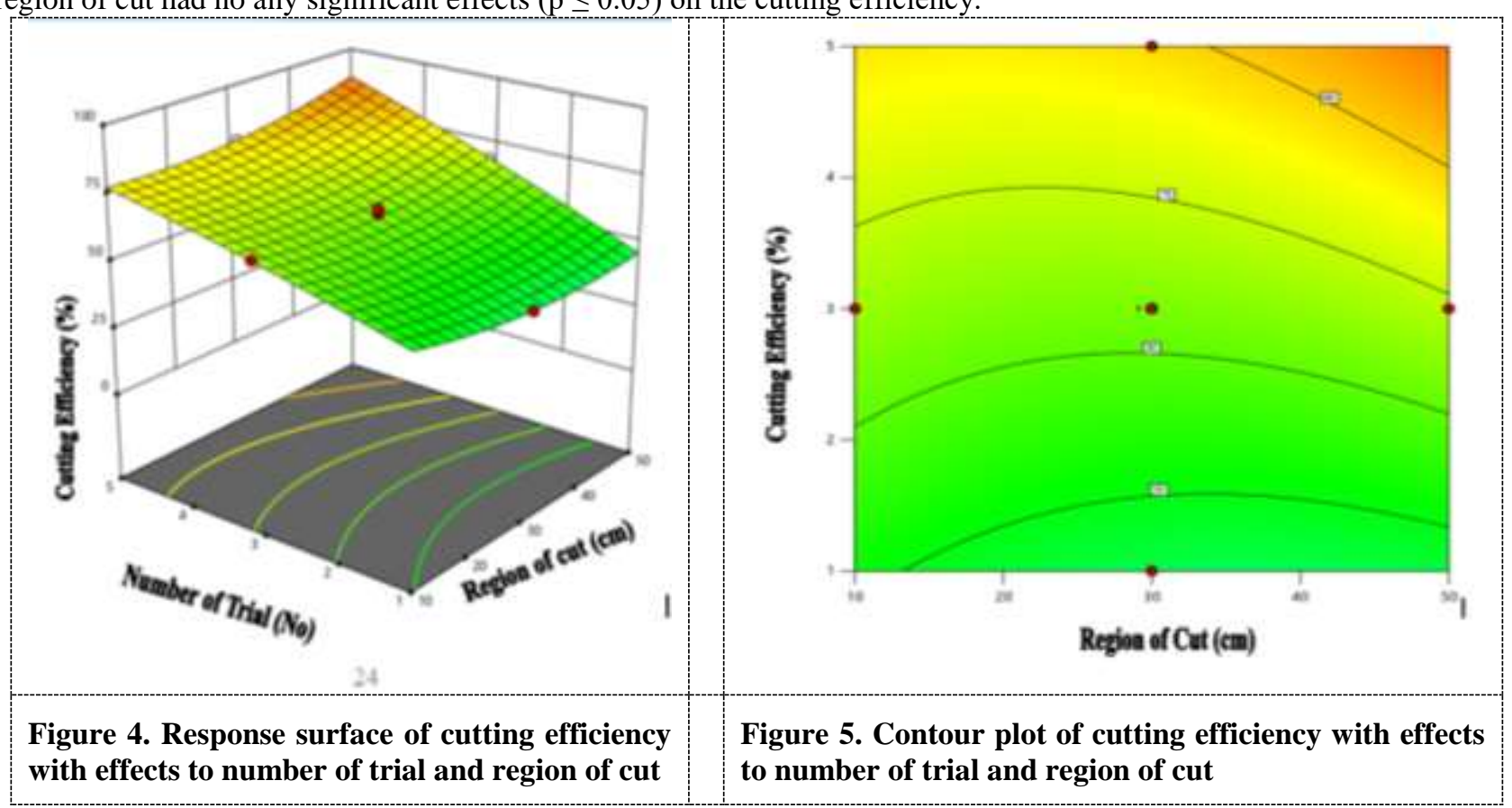

The optimization of the equipment parameters; stem moisture content (d.b), length of lever arm from fulcrum, region of cut above ground level and number of cutting attempts was carried out using numerical technique in rsm with the goal of maximizing the cutting efficiency. The ramp of the optimization process is shown in Figure 6 with optimum values of stem moisture content $75 \%$, length of lever arm from fulcrum of $70 \mathrm{~cm}$, region of cut above ground level of $40 \mathrm{~cm}$ and number of cutting attempts of 4 . This produced cutting efficiency of $99.5 \%$ with desirability of $94.89 \%$ and 0.959 . 

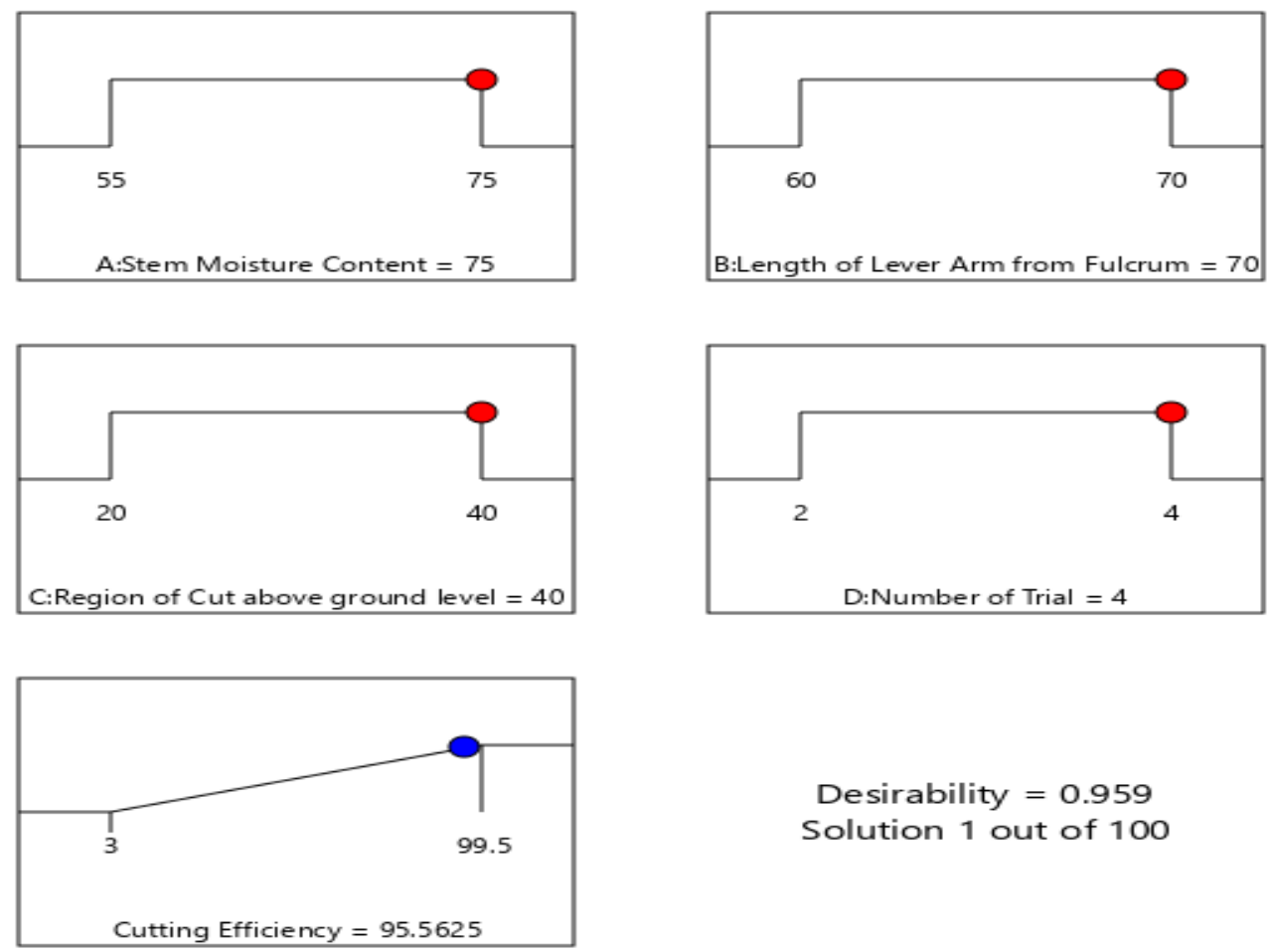

Desirability $=0.959$

Solution 1 out of 100

Figure 6: Ramp for Optimization of Machine Performance Parameters

\section{CONCLUSION}

The stem moisture content and number of cutting attempt had significant effects $(p \leq 0.05)$ on the cutting efficiency. While the length of the lever arm and region of cut had no any significant effects $(p \leq 0.05)$ on the cutting efficiency. The optimization of the equipment gives optimum values of stem moisture content $75 \%$, length of lever arm from fulcrum of $70 \mathrm{~cm}$, region of cut above ground level of $40 \mathrm{~cm}$ and number of cutting attempts of 4 . This produced cutting efficiency of $99.5 \%$ with desirability of 0.959 . Thus, indicating that, ease of cassava stem cutting will increase for stems with higher moisture levels than those with lower moisture and cutting is more certain at increased cutting attempts and vice versa.

\section{REFERENCES}

[1] Felber, C., Azouma, O. Y. and Reppich, M., "Evaluation of Analytical Methods for the Determination of the Physicochemical Properties of Fermented, Granulated and Roasted Cassava pulp, Garri”, Journal of Food Science and Nutrition, vol, 5, no. 1, pp. $46-53,2016$.

[2] Addy, P. S., Kashaija, I. N., Moyo, M. T., Quynh, N. K., Singh, S., and Walekhwa, P. N., Constraints and Opportunities for Small and Medium Scale Processing of Cassava in the Ashanti and BrongAhafo regions of Ghana. Working document series, International Centre for Development Oriented Research In Agriculture, vol, 117, pp. 60 $-69,2014$.

[3] Ennin, S. A., Otoo, E. and Tetteh, F. M., "Ridging: A Mechanized Alternative to Mounding for Yam and Cassava Production", West African Journal of Applied Ecology, vol, 15, pp. $1-8$

[4] Amponsah, S. K., Bobobee, E. Y. H., Agyare, W. A., Okyere, J. B., Aveyire, J., King, S. R, and Sarkodie-Addo, J., "Mechanical Cassava Harvesting as influenced by Seedbed Preparation and Cassava Variety", Applied Engineering in Agriculture, vol. 30, no. 3, pp. 391-403, 2014.

[5] Xue, Z., Zhang, J., Zhang. Y.L., Li, C.B. and Chen, S., "Test and Analysis on the Mechanical Properties of Cassava Stalks", Journal of Animal and Plant Sciences, vol. 25, no. 3, pp. 59 - 67.

[6] Kaewwinud, N., Khokhajaikiat, P. and Boonma, A., "Effect of Moisture and Region of Cut on Cassava Stalk Properties in Biomass Application”, Res. Agr. Eng., vol. 63, pp. 23 - 28.

[7] Egbe-Ogbengi, I.S and Agidi, G., "Development of a Hand Push-Type Cassava Harvester", Journal of Agricultural Engineering and Technology (JAET), vol. 24, no. 2, pp. $44-52$. 
[8] Babatunde O. S., Olugboyega C. A, and Leo Ayodeji S. A. "Determination of some physical and mechanical properties of soybean and maize in relation to planter design", Agric Eng Int: CIGR Journal, vol. 20, no. 1, pp. 8189, 2018.

[9] Gana I. M., Gbabo A., Peter A. I. and Anounye J. C. "Influence of Soaking on Moisture - Dependent Physical Properties of Some Selected Grains Essential to Design of Grain Drinks Processing Machine", TI Journals Agriculture Science Developments., vol. 3, no. 7, pp. 237-243, 2014.

[10] Tran, H.T., Phan, T.C.L., Tran, T.A.T., Ho, T.T., Le, T.V.H., Bui, H., "Using Central Composite Design-Response Surface Methodology to Optimize Inveratse Activity Condition For Fructose Production. Conference Proceedings of Biotechnology for Green Solutions and Sustainable Environment”, pp. 82-87, 2010.

[11] Gana I. M, Agidi G, Idah P. A. and Anuonye J. C. "Development and testing of An Automated Grains Drinks Processing Machine”, Food and Bioproducts Processing, vol. 104, pp. 19 - 31, 2017.

[12] Ogunlowo, Q. O. and Olaoye J. O., "Development and Performance Evaluation of a Guided Horizontal Conveyor Rice Harvester", Agrosearch, vol. 17, no. 1, pp. 66- 88, 2017.

[13] Aworanti, O.A., Agarry, A.O., Ajani, A.O., "Statistical Optimization of Process Variables for Biodiesel Production from Waste Cooking Oil using Heterogeneous Base Catalyst”, Br. Biotechnol. Journal, vol. 3, no. 2, pp. 116-132, 2013.

[14] Xin, L., Saka, S., "Optimization of Japanese Beech Hydrolysis Treated with Batch Hot Compressed Water by Response Surface Methodology”, Int. J. Agric. Biol. Eng., vol. 1, no. 2, pp. 239-245, 2008.

[15] Chih, W.T., Lee, I.T., Chung, H.W., "Optimization of Multiple Responses Using Data Envelopment Analysis and Response Surface Methodology”, Tamkang J. Sci. Eng., vol. 13, no. 2, pp. 197-203, 2017. 